\title{
Capsule Commentary on Fortuna et al., Health Conditions and Functional Status in Adults with Autism: A Cross Sectional Evaluation
}

\author{
Clarissa Kripke, MD, FAAFP
}

Office of Developmental Primary Care, Department of Family and Community Medicine, University of California, San Francisco, San Francisco, CA, USA.

J Gen Intern Med 31(1):106

DOI: $10.1007 / \mathrm{s} 11606-015-3537-6$

(c) Society of General Internal Medicine 2015

$\mathrm{S}$ tate and federal policy prioritizes serving people with disabilities in the community as opposed to in institutions. But there has been little investment in developing the health services and trained workforce to deliver effective medical care in this setting. Many studies have shown that overall, community-based services and small, fully-integrated housing is superior to institutions in a variety of domains, including community participation, contact with family and community, and quality of life. However, the research is more mixed in the areas of medication, health, risks, and mortality. Social determinants of health and problems with access to medical, dental and behavioral health care contribute to health disparities. ${ }^{1}$ Fortuna and colleagues' study expands our understanding of the health care and support needs of adults on the autism spectrum as they and their parents age. Autistic adults have higher rates of chronic medical conditions that require ongoing, medical attention, as well as significant, support needs for activities of daily living. ${ }^{2}$ Furthermore, most autistic adults live on their own or with family rather than in supervised residential settings. Due to advancements in federal Medicaid policy, the trend towards people with complex disabilities living in fully integrated homes will likely accelerate. The new Home and Community Based Settings regulation requires states to provide recipients of Medicaid-funded, long-term care with community options. Options must include the ability to choose service providers, housing, roommates and other relationships, supported employment in regular workplaces, and the ability to direct their own lives. ${ }^{3}$
Effective health care services and professional training requires the collaboration and leadership of autistic adults. To assist health care providers to serve the population, tools developed in collaboration with autistic adults have been developed by the Office of Developmental Primary Care (http://odpc.ucsf.edu) and the Academic-Autistic Spectrum Partnership in Research and Education (http://www. autismandhealth.org/). Also, review articles on primary care of transition age youth and adults are available to help clinicians and health systems provide culturally competent services to reduce health disparities and improve access to care. ${ }^{4,5}$

Corresponding Author: Clarissa Kripke, MD, FAAFP; Office of Developmental Primary Care, Department of Family and Community MedicineUniversity of California, San Francisco, 500 Parnassus Ave. MU318E, Box 0900, San Francisco, CA 94143-0900, USA (e-mail: kripkec@fcm.ucsf.edu).

\section{Compliance with Ethical Standards:}

Conflict of Interest: The authors declare that they do not have a conflict of interest.

\section{REFERENCES}

1. Mansell J, Beadle-Brown J, Special Interest Research Group. Deinstitutionalization and community living: position statement of the comparative policy and practice special interest research group of the international association for the scientific study of intellectual disabilities. J Intel Dis Res. 2010;54(2):104-12.

2. Fortuna RJ, Robinson L, Smith TH, Meccarello J, Bullen B, et al. Health conditions and functional status in adults with autism: a cross sectional evaluation. J Gen Intern Med. 2015. doi:10.1007/s11606-015-3509-x.

3. Autistic Self-Advocacy Network. ASAN Toolkit on Improving Home and Community-Based Services (HCBS). Available at: http://autisticadvocacy. org/policy-advocacy/policy-advocacy-toolkits/hcbs/. Accessed 8/26/15.

4. Nicolaidis C, Kripke C, Raymaker D. Primary care for adults on the autism spectrum. Med Clin North Am. 2014;98(5):1169-91.

5. Kripke CC. Primary care for adolescents with developmental disabilities. Prim Care. 2014;41(3):507-18.

Published online November 5, 2015 